\title{
The effect of soil redistribution on soil organic carbon: an experimental study
}

\author{
H. Van Hemelryck ${ }^{1,5}$, P. Fiener ${ }^{2}$, K. Van Oost ${ }^{3}$, G. Govers ${ }^{1}$, and R. Merckx ${ }^{4}$ \\ ${ }^{1}$ Division of Geography, Department of Earth and Environmental Sciences, K. U. Leuven, Leuven, Belgium \\ ${ }^{2}$ Geographisches Institut der Universität zu Köln, Köln, Germany \\ ${ }^{3}$ Earth and Life Institute, Georges Lemaitre Centre for Earth and Climate Research (TECLIM), Université catholique de \\ Louvain, Louvain, Belgium \\ ${ }^{4}$ Laboratory of Soil and Water Management, Department of Earth and Environmental Sciences, K. U. Leuven, \\ Leuven, Belgium \\ ${ }^{5}$ Aspirant, Fonds voor Wetenschappelijk Onderzoek, Vlaanderen, Belgium
}

Received: 3 April 2009 - Published in Biogeosciences Discuss.: 14 May 2009

Revised: 24 September 2010 - Accepted: 24 September 2010 - Published: 7 December 2010

\begin{abstract}
Soil erosion, transport and deposition by water drastically affect the distribution of soil organic carbon (SOC) within a landscape. Furthermore, soil redistribution is assumed to have a large impact on the exchange of carbon (C) between the pedosphere and the atmosphere. There is, however, significant scientific disagreement concerning the relative importance of the key-mechanisms at play. One of the major uncertainties concerns the fraction of SOC that is mineralized when soil is eroded by water, from the moment when detachment takes place until the moment when the SOC becomes protected by burial. In this study, the changes in $\mathrm{C}$-exchange between soil and atmosphere as affected by soil redistribution processes were experimentally quantified. During a laboratory experiment, three types of erosional events were simulated, each of which was designed to produce a different amount of eroded soil material with a different degree of aggregation. During a 98-day period, $\mathrm{CO}_{2}$-efflux was measured in-situ and under field conditions on undisturbed soils with a layer of deposited soil material. Depending on the initial conditions of the soil and the intensity of the erosion process, a significant fraction of eroded SOC was mineralized after deposition. However, results also suggest that deposition produces a dense stratified layer of sediment that caps the soil surface, leading to a decrease in SOC decomposition in deeper soil layers. As a result, the net effect of erosion on SOC can be smaller, depending on the
\end{abstract}

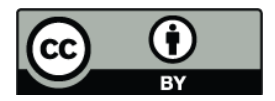

Correspondence to: P. Fiener (peter.fiener@uni-koeln.de) functioning of the whole soil system. In this study, soil redistribution processes contributed an additional emission of 2 to $12 \%$ of total $\mathrm{C}$ contained in eroded sediment.

\section{Introduction}

Soil erosion, transport and deposition by water and tillage drastically affect the distribution of soil organic carbon (SOC) within a landscape (Ritchie and McCarty, 2003; Zhang et al., 2006). Furthermore, soil redistribution is assumed to have a large impact on the exchange of carbon (C) between the pedosphere and the atmosphere, through its influence on both input rates of $\mathrm{C}$ to the soil and changes in decomposition of SOC (Lal, 2003; Smith et al., 2005; Stallard, 1998; Gregorich et al., 1998; Harden et al., 1999; Liu et al., 2003; Van Oost et al., 2007; Yoo et al., 2005). Three key mechanisms could be identified, which can alter the flux of $\mathrm{C}$ between the soil and the atmosphere: (i) Dynamic replacement: at eroding sites, the depleted SOC pool can, at least partially, be replaced by newly assimilated C (Harden et al., 1999). Continued C input and a decrease in SOC available to decomposition can lead to a net gain of $\mathrm{C}$ at these sites. (ii) Burial of topsoil SOC and reduced decomposition: as suggested by Stallard (1998), the rate of decomposition of SOC in depositional settings can be reduced due to a combination of physical and chemical processes, such as increased soil wetness, limited aeration, compaction and physical protection of the deposited soil material within newly formed aggregates (Gregorich et al., 1998; De Gryze et al., 2007),

Published by Copernicus Publications on behalf of the European Geosciences Union. 
leading to a preservation of buried C. (iii) Transport and increased decomposition: the disruptive energy of forces applied to the soil by water erosion (raindrop impact, the shearing force of flowing water and collision with other aggregates), may cause the breakdown of aggregates (Lal, 2003). This process of disaggregation exposes previously protected SOC to microbial decomposition and combined with a relatively greater proportion of labile SOC within larger soil aggregates (Six et al., 2000) could lead to rapid mineralization of this easily decomposable $\mathrm{C}$ following water erosion.

It must also be noted that part of the eroded SOC is transported to distal environments and fluvial systems. Its fate, however, is still largely unclear though recent research suggests that even old SOC may become mineralized when transported in water (Cole and Caraco, 2001).

Concerning the relative importance of the abovementioned key mechanisms there is, however, significant scientific disagreement. Together with a lack of process knowledge, opposing assumptions hamper an accurate estimation of the impact of soil redistribution on the terrestrial carbon balance (Berhe et al., 2007). Notwithstanding this ongoing debate, it is generally agreed that the soil system potentially plays a major role in controlling atmospheric carbon dioxide concentrations (Amundson, 2001). Globally, the soil reservoir stores approximately $2344 \mathrm{Pg} \mathrm{C}$ in the top $3 \mathrm{~m}$ (1502 Pg C in the first meter) (Jobbagy and Jackson, 2000). Even a small additional relative flux to/from this system as a result of increased storage/respiration of SOC through soil erosion, could substantially affect soil carbon storage and atmospheric $\mathrm{CO}_{2}$ concentrations. Attempts to globally assess this effect by linking carbon dynamics to soil erosion and deposition patterns resulted in the assertion of a net sink of 1.0 $\mathrm{Pg} \mathrm{C} \mathrm{yr}^{-1}$ (Smith et al., 2005) up to $1.5 \mathrm{Pg} \mathrm{C} \mathrm{yr}^{-1}$ (Stallard, 1998) as well as a net source of $1.1 \mathrm{Pg} \mathrm{Cyr}^{-1}$ (Lal, 2003). More recently, and based on an integrated study of the different, simultaneously occurring processes and their interactions, an erosion-induced sink of $0.12 \mathrm{Pg} \mathrm{C} \mathrm{yr}^{-1}$ on global agricultural land was proposed (Van Oost et al., 2007).

One of the major uncertainties concerns the fraction of SOC that is mineralized when soil is eroded by water, from the moment when detachment takes place until the moment when the SOC becomes protected due to burial (Lal, 2003), and this is the major focus of this study.

Published estimates of this fraction are often indirectly obtained and vary widely. Based on the distribution of soil organic matter components along an eroded soil catena, Beyer et al. (1993) estimated 70\% of the non-humin fraction of soil C in colluvial material to be decomposed during translocation or shortly after deposition. Jacinthe et al. (2001) compared SOC inventories and quality of SOC on cropland and adjacent depositional zones. The pools of labile $\mathrm{C}$ in the deposits (on average 9\% of total SOC) were 20 to $46 \%$ lower than expected. The latter could be interpreted as the result of mineralization of labile $\mathrm{C}$ pools during transport and deposition. When combining inventories of SOC and erosion tracers from a wide range of agricultural soils to derive evidence for erosion-induced carbon dynamics, Van Oost et al. (2007) concluded that losses of $\mathrm{C}$ associated with transport are relatively minor and that most deposited $\mathrm{C}$ is effectively preserved.

The few experimental studies, in which estimates of eroded $\mathrm{C}$ mineralization are supported by direct quantitative data, neither succeed to provide a unique answer. Jacinthe et al. (2002) measured the $\mathrm{CO}_{2}$-efflux from incubated samples of runoff, generated during simulated rainfall events on different small soil blocks. Despite large differences in sediment delivery rate and initial soil $\mathrm{C}$ content, a consistent 31 to $37 \%$ of total eroded $\mathrm{C}$ was found to be potentially mineralizable. Polyakov and Lal (2004) subjected five soil plots, positioned at different slopes and connected in a cascade fashion, to simulated rainfall. Subsequently, $\mathrm{CO}_{2}$-efflux from undisturbed soil samples taken on erosion and deposition plots was measured during an incubation experiment. On the soil samples with deposition, $15 \%$ of the deposited $\mathrm{C}$ mineralized during the experiment, resulting in a $26 \%$ higher emission of $\mathrm{CO}_{2}$, compared to the control sites. There was no significant difference in mineralization of $\mathrm{C}$ between the eroded soil samples and the control soil samples. Jacinthe et al. (2004) incubated runoff samples collected during a one-year period at the outlet of small watersheds under cultivation. Mineralizability of eroded $\mathrm{C}$, proved to be dependent on the rainstorm type, generating the runoff and varied from 30-40\% for low-energy rainstorms, to only $13 \%$ during high-intensity storms.

Thus, relatively few data are available with respect to the mineralization of SOC as affected by erosion, transport and subsequent deposition. Moreover the estimates thus far show considerable variation. Various factors explain the ambiguities: first of all, the mineralizable fraction of eroded SOC often is estimated as the potentially mineralizable C, measured during an incubation of soil samples. An alternative would be to measure effective in-situ mineralization under field conditions. Furthermore, different things are measured: while in some studies, measurements were done on disturbed runoff samples, intact soil samples are used in others. Experimental and field conditions also vary widely and the effect of variations in initial soil conditions and/or erosion intensity are not well understood. It may be hypothesised that the degree of aggregate disruption during erosion and transport plays an important role in subsequent SOC mineralization (Jacinthe et al., 2004).

The main objective of this study is therefore to experimentally quantify the changes in $\mathrm{C}$ exchange between soil and atmosphere as affected by erosion in case of different initial soil conditions and erosion rates used to simulate typical agricultural erosion events. 


\section{Materials and methods}

\subsection{Experimental design}

Three types of simulation experiments were conducted, each of which was designed to produce a different amount of eroded soil material and different levels of aggregation. For each type of simulation experiment, 2 replicates were performed. An overview of the experimental set-up, based on the set-up used by Beuselinck et al. (1999), is presented in Fig. 1. The eroded sediment was deposited in a depositional area. These depositional areas consisted of $2.25 \mathrm{~m}$ long, $0.61 \mathrm{~m}$ wide and $0.25 \mathrm{~m}$ deep soil trays set at zero slope. The trays were filled with $0.22 \mathrm{~m}$ of soil taken from the top $0.15 \mathrm{~m}$ soil layer of an arable field close to Leuven, Belgium. The soil is a typical silt loam of the Belgium Loess Belt with an average sand, silt and clay content of respectively $20 \%$, $73 \%$ and $7 \%$ and an average SOC content of $1.52 \%$. To fill the trays as homogeneously as possible, the used soil was air-dried and sieved at $0.02 \mathrm{~m}$ before filling. To reach a bulk density comparable to that of arable land, the depositional trays were filled in layers of ca. $0.03 \mathrm{~m}$. Each layer was similarly moistened and compacted to obtain an average dry bulk density of $1.39 \times 10^{6} \mathrm{~g} \mathrm{~m}^{-3}$. The bottom of the tray was perforated, to allow drainage, and covered with a water permeable textile to avoid clogging of the percolation holes with soil material. In total, eight soil beds were prepared in identical soil trays, six as depositional areas for the experimental runs and two as control soil beds.

In general, sediment input into the depositional areas was produced with two set-ups. On the one hand, a clear water flow was applied over an erosion flume $(2.32 \mathrm{~m}$ long $\times 0.60 \mathrm{~m}$ wide $\times 0.24 \mathrm{~m}$ deep, set at $15^{\circ}$ slope), connected at its lower edge to the depositional tray and filled with $0.18 \mathrm{~m}$ of soil, analogously to the depositional areas. The surface runoff water was supplied from a small overflow basin at the upslope end of the flume equipped with a flow control device to ensure a fixed inflow discharge (Fig. 1a). On the other hand, a homogeneous mixture of soil and water was pumped directly onto the depositional area (Fig. 1b).

In detail, the following three experimental procedures were used:

i. One set of two replicate runs was carried out after filling the erosion flume with moistened soil material over which a clear water flow was applied (wet soil runs, abbreviated WSR). Using a relatively high inflow discharge, rill flow conditions, optimal for unselective erosion of aggregated sediment, were simulated (Beuselinck et al., 2000). The high initial moisture content of the soil greatly enhanced the erosion resistance of the loamy soil, likely resulting in a decreased sediment production on the erosion flume (Govers et al. , 1990). The soil was moistened no longer than $24 \mathrm{~h}$ before the experiment was carried out.

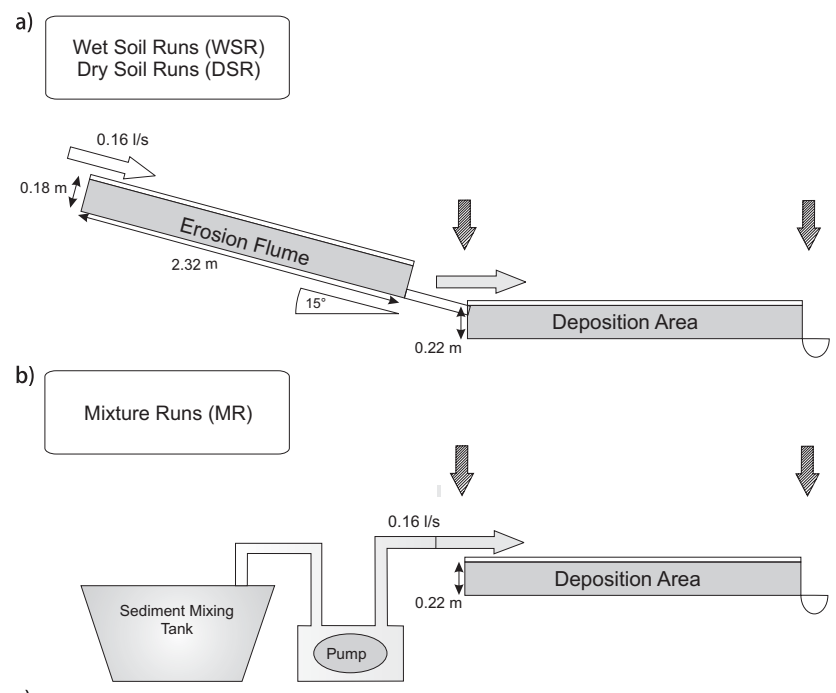

c)

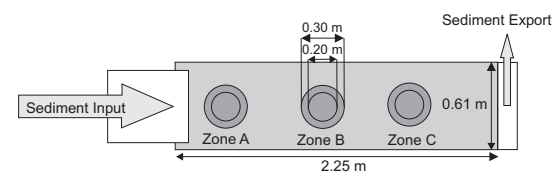

Fig. 1. Schematic sideview diagram of of experimental set-up for the three types of simulation experiments: (A) wet soil runs (WSR), dry soil runs (DSR) and (B) mixture runs (MR). (C) Top view diagram of the depositional area with deposition zones A, B and $\mathrm{C}$ and location of inner and outer PVC rings, extracted for $\mathrm{CO}_{2}$-efflux measurements. Vertical arrows in (A) and (B) indicate runoff sampling locations.

ii. In a second set of two runs, the same procedure as for the WSR was used with the exception that the center section of the erosion flume $(2.32 \mathrm{~m}$ long $\times 0.15 \mathrm{~m}$ wide $\times 0.08 \mathrm{~m}$ deep) was filled with air-dried soil rather than moistened soil (dry soil runs, abbreviated DSR). Upon rapid wetting, slaking of some dry soil aggregates, i.e. breakdown due to compression of air entrapped within the aggregates, is assumed to occur (Kemper et al., 1985; Le Bissonnais, 1996). Subsequently the resultant soil material is more easily entrained by the water flow leading to higher erosion rates in the erosion flume and consequently higher deposition rates in the depositional area (Govers, 1991).

iii. During the last pair of runs, a homogeneous mixture of soil and water, with a sediment concentration of $150 \mathrm{~kg} \mathrm{~m}^{-3}$ was prepared in a $0.8 \mathrm{~m}^{3}$ mixing tank and pumped directly into the depositional area (mixture runs, abbreviated MR). Continuous mixing of the water and sediment using a centrifugal pump ensured that aggregates were largely destroyed prior to the experiment. As such, this set-up simulated interrill flow, transporting detached primary soil particles after aggregate breakdown by raindrop impact or dispersion in water 
(Di Stefano and Ferro, 2002). For practical reasons, the MR were conducted 50 days after the WSR and DSR.

All experimental runs lasted $15 \mathrm{~min}$, except for the WSR, which lasted $30 \mathrm{~min}$ in order to create a sufficient amount of deposition, despite the low erosion rates. During all runs, an inflow discharge of about $1.6 \times 10^{-4} \mathrm{~m}^{3} \mathrm{~s}^{-1}$ was used.

The set-ups of the experiments as described above, closely resembled different agricultural erosion events, typical for the region of Belgium (Steegen, 2001). While the DSR simulated a typical summer erosion event after a period of drought, the MR reproduced a winter event after prolonged rainfall broke down soil aggregates to a great extent. The WSR were intermediate between DSR and MR, representing an erosion event in case of a moist and well-structured soil.

\subsection{Measuring sediment and SOC delivery and sampling of deposition}

In order to calculate the fluxes of sediment and SOC through the system, 200-800 ml runoff samples were collected at the in- and outlet of the depositional area at regular time intervals (every 4 min during WSR, every 2 min during DSR and MR).

After each experimental run, the depositional area was divided into three zones $(\mathrm{A}, \mathrm{B}, \mathrm{C})$ along the direction of the water flow with zones $\mathrm{A}$ and $\mathrm{C}$ closest to the inlet and the outlet of the depositional area, respectively (Fig. 1c). In each zone and in the control soils, a cylindrical sample of the topsoil $\left(0.05 \mathrm{~m}\right.$ depth, $\left.100 \mathrm{~cm}^{3}\right)$ was taken to determine the soil dry bulk density.

Next, an inner and an outer PVC ring were inserted into the deposited sediments and the original soil bed of all depositional zones (A, B and C), thereby carefully avoiding disruption of the soil structure. The outer ring $(\varnothing 0.3 \mathrm{~m})$ was inserted to the bottom of the deposition tray and created a buffer zone around the inner ring $(\varnothing 0.2 \mathrm{~m})$, which was introduced to a depth of $0.1 \mathrm{~m}$. Next, the rings and the undisturbed soil cores within, were carefully excavated and transferred to a sand box with an adjustable water table, to allow the soil cores to drain and equilibrate to a constant soil moisture content (Fig. 2a). Using an identical procedure, three undisturbed soil cores were sampled from the control soil beds (further termed "control soil(s) cores"), which were prepared similarly to the depositional soil beds but not exposed to water flow and onto which no sediment was deposited.

The inner rings were later on used to measure $\mathrm{CO}_{2}$-efflux during a consecutive 98-day period. After the $\mathrm{CO}_{2}$-efflux measurement period, the soil cores were sliced up longitudinally so that the thickness of the sediment deposit could be determined (Fig. 2b). Next the deposited soil was sampled carefully, in order not to include any soil material from the original soil bed.

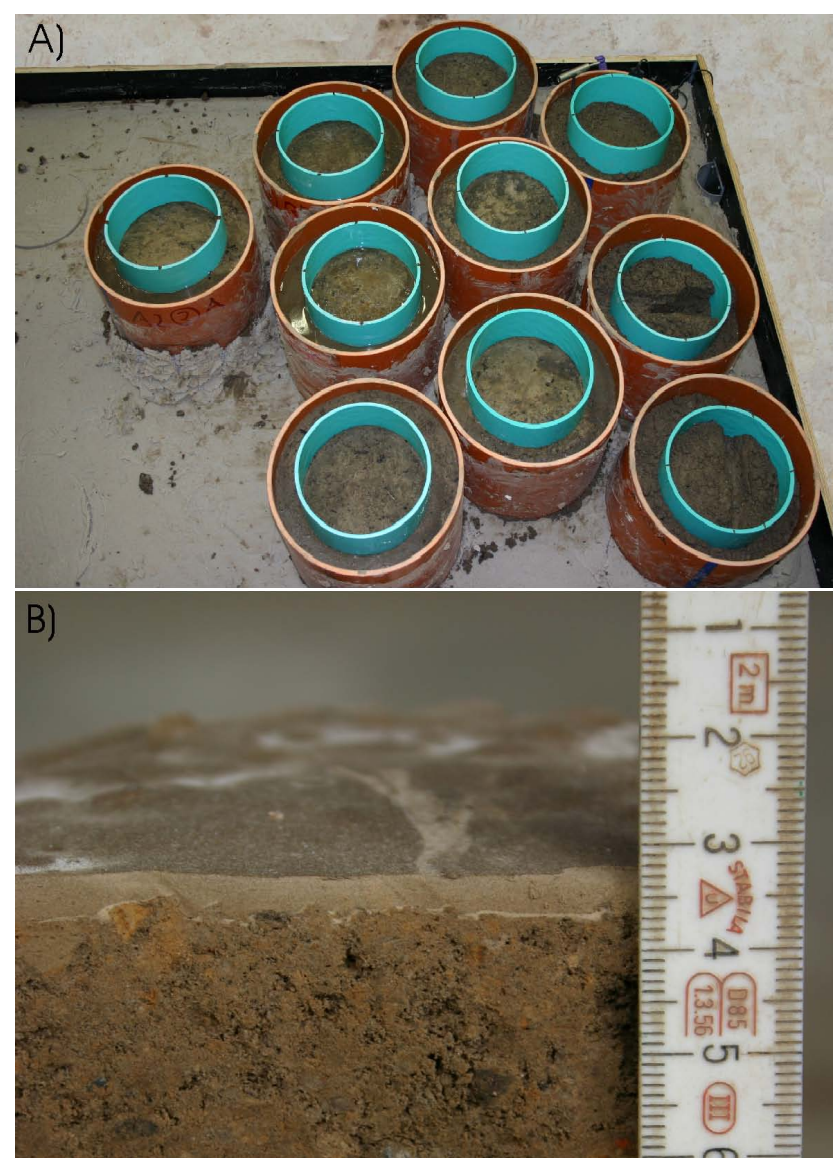

Fig. 2. (A) Sand box with undisturbed soil cores from deposition zones. (B) Cross-section of soil core, sampled after the mixture runs with a $0.5 \mathrm{~cm}$ deposition layer clearly visible on top of the original soil bed.

\subsection{Sediment and SOC laboratory analyses}

All soil samples (from parent soil, deposited sediment and collected runoff) were oven-dried at $45^{\circ} \mathrm{C}$ for three days. The runoff samples were weighed to determine the sediment concentration. Dried samples were ground with a mortar and pestle. The grain-size distribution of the deposited sediment was determined using a Coulter Counter LS 13320 laser diffraction particle size analyser (Beckman Coulter, USA). To determine SOC concentration an ANCA 20-20 GSL mass spectrometer (Sercon Ltd, UK) was used. Although the objective of this study is not to assess the relationship between aggregate breakdown and $\mathrm{C}$ dynamics, some additional measurements were carried out to determine the impact of wetting on aggregate structure and carbon distribution in the soils used in this study. This was done mainly in order to direct possible further research. The methodology used for these measurements was adapted from Elliott (1986). Two sets of three 50-g subsamples were taken from the original soil, after this was passed through a large meshed sieve and 
air dried. Aggregate separation of these samples was done by wet sieving. However, for the two sample sets, a different pretreatment was applied: (i) for the first set the air-dried soil was rapidly immersed in water (initiating slaking) while (ii) for the second set the air-dried soil was slowly wetted to field capacity before immersion in water (to a soil moisture content similar as in WSR). As such, the wet sieving treatment resembled the erosion process for the DSR (i) and the WSR (ii) in the original experiments. Next, the soil samples were submerged in water on a $2000 \mu \mathrm{m}$ sieve for $5 \mathrm{~min}$. Subsequently the soils were sieved under water by gently moving the sieve up and down $3 \mathrm{~cm}$ for 50 times in $2 \mathrm{~min}$. Soil material remaining on the sieve was oven-dried and weighed. The material $<2000 \mu \mathrm{m}$ was collected and the sieving procedure was repeated for sieve sizes of $250 \mu \mathrm{m}$ and $53 \mu \mathrm{m}$, thereby separating the original soil samples in 4 aggregate size fractions. Total organic $\mathrm{C}$ content of each aggregate fraction was determined by high temperature combustion using a Variomax CN analyzer (Elementar Analysensysteme, Germany).

\subsection{Calculation of sediment and SOC balances}

The amount of deposited sediment and SOC can be calculated in two distinct ways. In a first method (M1), a sediment mass balance is computed as the difference between the inand output of sediment in the depositional area. The input (output) of sediment in/from the depositional area was calculated as the area under the curve of sediment discharge at the inlet (outlet) of the depositional area (further abbreviated as sediment inflow and sediment outflow, respectively) during an experimental run. The mass of SOC, deposited in the depositional area, was similarly calculated as the difference between the time-integrated product of sediment discharge and SOC concentration at the inlet and outlet of the depositional area.

In a second method (M2), the amount of deposited sediment and SOC can in principle be calculated by extrapolating the mass of deposited sediment and SOC, contained within the extracted PVC rings, to the whole depositional area. As this method was based on the results of measurements on soil samples, taken at the end of the $\mathrm{CO}_{2}$-efflux measurements (98 days), the thus estimated amount of SOC in the deposited sediment has to be considered the SOC, remaining after 98 days of $\mathrm{CO}_{2}$-efflux measurements. Concerning the estimated amount of sediment, it can be assumed that no sediment moved from the depositional area during the $\mathrm{CO}_{2}$-efflux measurements. Using $\mathrm{M} 2$, we however need to account for the fact that the distribution of deposited sediment as well as SOC was spatially non-uniform. The volume of the deposited sediment layer on an undisturbed soil core, excavated from zone A, B or C in the depositional area, was estimated based on five measurements of the deposition layer thickness. In the depositional area, the eroded sediment was deposited in a wedge-shaped layer, as runoff was constrained within the sidewalls of the deposition tray. Therefore the estimated volume of deposited sediment per unit area for one soil core could be assumed to approximate the average volume of deposited sediment per unit area in the rectangular zone (A, B or C) centred around this soil core. The total mass of deposited sediment in the depositional area was then calculated as:

$M=\sum_{i=\mathrm{A}, \mathrm{B}, \mathrm{C}} \frac{\mathrm{SedVol}_{\text {ring }, i}}{A_{\text {ring }}} \times A_{i} \times \mathrm{BD}_{i}(\mathrm{~g})$

where $M$ is the total mass of sediment deposited in the depositional area, sedVol ${ }_{\text {ring, } i}$ is the estimated volume of the deposited sediment within a PVC ring, sampled from zone A, $\mathrm{B}$ or $\mathrm{C}, A_{\text {ring }}$ is the area of the upper surface of a PVC ring, $\mathrm{BD}_{i}$ is the soil dry bulk density in zone $\mathrm{A}, \mathrm{B}$ or $\mathrm{C}$ and $A_{i}$ is the surface area of the rectangular zone A, B or C.

Based on the sample location of the undisturbed soil cores, the lengths of the rectangular zones A, B and C were 0.57 , 0.57 and $1.11 \mathrm{~m}$ respectively. The width of all rectangular zones was equal to the width of the depositional tray $(0.61 \mathrm{~m})$.

Next the mass of deposited sediment calculated using M2, was compared with the mass of deposited sediment calculated using M1. If the mass of deposited sediment, as calculated by both methods, differed by more than $5 \%$, the surface area of zones A, B and C was slightly altered until the recalculated mass of deposited sediment in M2 matched the mass of deposited sediment according to M1. Total deposited SOC, still present after the $\mathrm{CO}_{2}$-efflux measurements, was then calculated as the product of the mass of deposited sediment in zones A, B and C and the SOC concentration in the layer of deposited sediment within the corresponding soil rings. This calculation methodology furthermore allows for an estimation of the distribution of deposited sediment and SOC (after $\mathrm{CO}_{2}$-efflux) along the flow direction in the depositional area. The two independent estimates of SOC in the deposited sediment before and after 98 days of $\mathrm{CO}_{2}$-efflux measurements can be evaluated in function of the measured cumulative $\mathrm{CO}_{2}$-efflux.

\subsection{Measuring $\mathrm{CO}_{2}$-efflux, soil temperature and moisture}

$\mathrm{CO}_{2}$-efflux, soil temperature and soil moisture were measured on the undisturbed soil cores, sampled in the zones of the depositional area of each replicated experimental run (number of replicates is 2), after they were placed on a sand box for drainage. Additionally, measurements were carried out on the "control soil cores", which were sampled from the control soil beds onto which no sediment was deposited. These measurements were used as a reference to which $\mathrm{CO}_{2}$ efflux from soil cores, sampled in soil beds with deposited sediment was compared. Measurements on WSR, DSR and control soil cores were carried out for 98 days, while for 
technical reasons the MR were shifted by 50 days and hence measurements on MR soil cores only lasted 48 days.

The sand box with the soil cores was initially placed inside the laboratory, where diurnal air temperature variations were limited. After 77 days, no noticeable changes in $\mathrm{CO}_{2}$-efflux from the soil columns were observed. A further continuation of the measurements was therefore not considered to be useful. We thereupon moved the soil columns to an outside location, where they were protected from rainfall, so that additional information on the effects of drying and temperature variation on $\mathrm{CO}_{2}$-efflux could be collected. This phase of the experiment was considered to be exploratory only and was therefore limited to 20 days. The measurements in the outside environment, however, did allow to postulate hypotheses, which could inspire discussion and direct possible further research.

During the measurement period, $\mathrm{CO}_{2}$-efflux, temperature and moisture were measured at increasing time intervals (from two times daily to twice a week). Measurements were always performed in the late afternoon. $\mathrm{CO}_{2}$-efflux from the inner soil core, was monitored using a LI-COR 8100103 survey chamber $(\varnothing 0.2 \mathrm{~m})$ and a LI-COR LI-8100 infrared gas analyser (LI-COR, USA). Temperature and volumetric moisture content of the soil cores were measured, with a TESTO 110 soil thermometer (TESTO, Belgium) and a $0.16 \mathrm{~m}$, two-rod time domain reflectometry, TRIMEEZ probe, connected to a TRIME-HD display device (Imko $\mathrm{GmbH}$, Germany), respectively. As a result of a malfunction of the soil moisture measurement device, measurements taken on DSR soil cores, during the last 14 days of the measurement period were incorrect and left out of the study.

The cumulative $\mathrm{CO}_{2}$-efflux on all soil cores was approximated as an area under the curve (AUC) over the measurement period. For comparison reasons, the cumulative $\mathrm{CO}_{2}$ efflux, evolved from MR-soil cores over the course of the 27-day measurement period inside the laboratory, was linearly extrapolated over a 77-day period, as this was the measurement period for WSR, DSR and control soil cores. Inside the laboratory, diurnal temperature variation was limited and hence measured $\mathrm{CO}_{2}$-effluxes should well represent the daily average $\mathrm{CO}_{2}$-efflux. For the 21 days of measurements in open air, however, the afternoon measurements of $\mathrm{CO}_{2}$-efflux most likely represent an overestimate of the daily average $\mathrm{CO}_{2}$-effluxes.

\subsection{Statistical analysis of $\mathrm{CO}_{2}$-efflux, soil temperature and moisture}

The effect that the amount of deposited sediment and its degree of aggregation has on variations in $\mathrm{CO}_{2}$-efflux, soil temperature and soil moisture, was examined using a repeated measures ANOVA with PROC MIXED in SAS 9.1 software (SAS Institute Inc., USA). Each simulation experiment (WSR, DSR and MR) and each zone in the depositional area (A, B and C) was considered a different "treatment" of a reference soil by adding a layer of deposited sediment of certain thickness and varying degree of aggregation. The measurements on the undisturbed soil cores, sampled on similar locations in the depositional area after the two experimental runs, were considered as replicates. The repeated measures ANOVA allows for the comparison of "treatments" averaged over time as well as for the detection of any time trends. In addition to a univariate ANOVA, repeated measures analysis accounts for the correlation over time between measurements on one soil core (Hedeker and Gibbons , 2006; Littell et al., 1998). As such it was possible to detect any statistically significant difference in the measured $\mathrm{CO}_{2}$-efflux, soil temperature and soil moisture between undisturbed soil core samples from the three different simulation experiments and/or zones of the depositional area.

The analyses were conducted separately on the measurements inside and outside the laboratory as measurements are influenced differently by varying environmental conditions between both periods. Statistical comparison of the measurements on the MR soil cores versus measurements on the DSR and WSR soil cores, was done, assuming that all experimental runs were conducted on the same day. However, for clarity reasons, in all graphs of measurements versus time, results were plotted relative to the day on which WSR and DSR were conducted (defined as day 0). For all statistical tests, statistical significance was accepted at $p \leq 0.05$. All values in this paper are reported as mean $\pm \mathrm{SE}$, unless otherwise stated.

\section{Results}

\subsection{Runoff of sediment and SOC}

Runoff from the erosion flume (only during WSR and DSR) began on average two minutes after initiation of the water flow at the upslope end of the flume. Two minutes after runoff generation, the sediment-laden water reached the end of the depositional area.

The controlled inflow discharge remained fairly constant $\left(1.60 \pm 0.02 \times 10^{-4} \mathrm{~m}^{3} \mathrm{~s}^{-1}\right)$ throughout all experimental runs. The steady-state outflow discharge averaged over all experimental runs amounted to $1.20 \pm 0.20 \times 10^{-4} \mathrm{~m}^{3} \mathrm{~s}^{-1}$, with the higher variability between experimental runs probably resulting from differences in soil moisture content of the depositional soil beds before the simulation experiment. The average runoff ratio for the depositional areas in these experiments was therefore $0.70 \pm 0.07$.

Sediment inflow and sediment outflow varied distinctly within and between experimental runs (Fig. 3a). During the WSR experiments, sediment loss from the erosion flume was low and relatively constant throughout the duration of the experimental runs (average sediment inflow of $4.2 \mathrm{~g} \mathrm{~s}^{-1}$ ). A small rill incised in the erosion flume soil bed and gradually extended upslope, mainly by back-cutting from the outlet of 

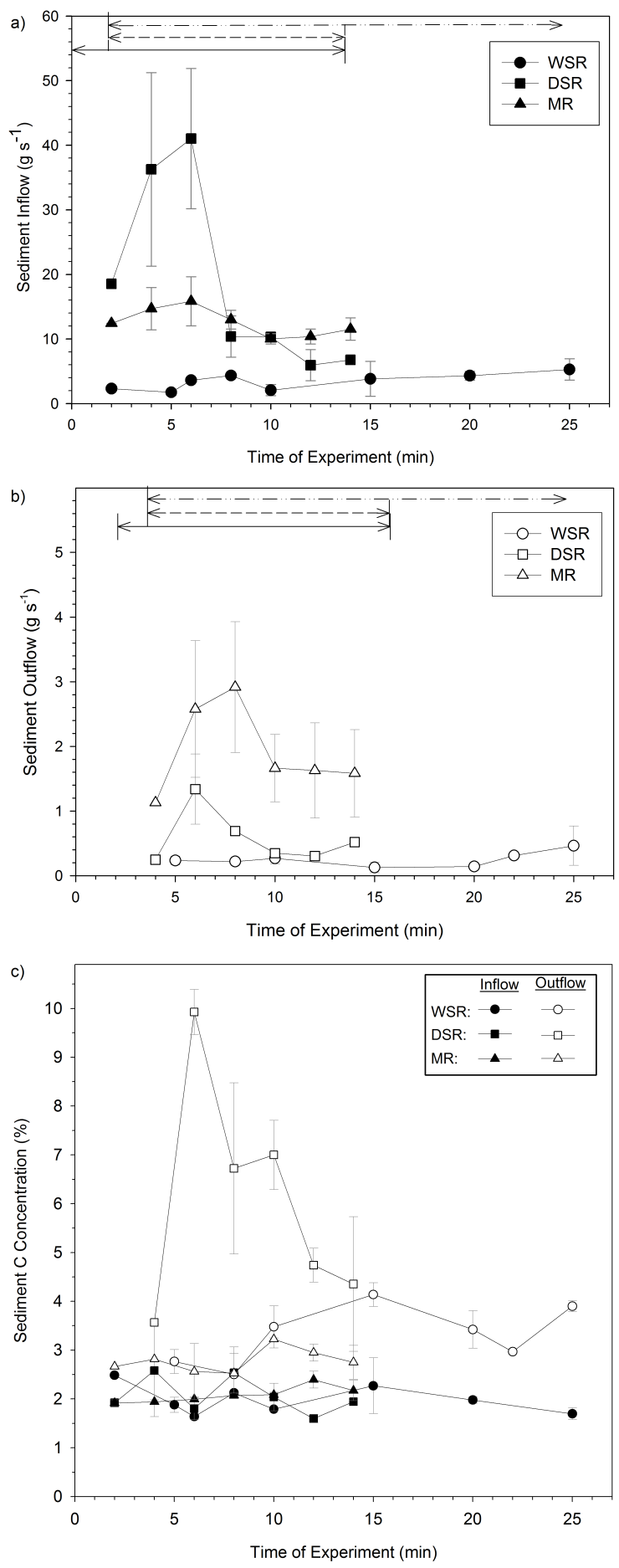

Fig. 3. (a) Sediment inflow $\left(\mathrm{g} \mathrm{s}^{-1}\right)$, defined as sediment discharge measured at the inlet of the depositional area for the three simulation experiments (average of replicate runs). (b) Sediment outflow $\left(\mathrm{g} \mathrm{s}^{-1}\right)$, defined as sediment discharge measured at the outlet of the depositional area for the three simulation experiments (average of replicate runs). (c) Sediment carbon concentration (\%) in runoff at the inlet (gray) and outlet (white) of the depositional area for the three simulation experiments (average of replicate runs). The arrows mark the duration of runoff for each experiment: WSR (dotdashed), DSR (dashed), MR (full line). Error bars indicate the standard error of the mean. the erosion flume. In contrast to this gradual erosion process, the measured sediment inflow was high during the first 7 min of the DSR experiments (average sediment inflow of $34.6 \mathrm{~g} \mathrm{~s}^{-1}$ ) but decreased for the remainder of the dry soil experimental runs to an average sediment inflow of $8.3 \mathrm{~g} \mathrm{~s}^{-1}$. These measurements are consistent with the observation of the rapid washing out of the air-dried soil from the centre section of the erosion flume in the beginning of these experiments. During the MR experiments, a homogeneous mixture of dispersed soil and water was pumped directly into the deposition area with a controlled inflow discharge. This resulted in a relatively constant initial sediment inflow (average sediment inflow of $13.8 \mathrm{~g} \mathrm{~s}^{-1}$ during the first $7 \mathrm{~min}$ of the experiments). The slight decrease in sediment inflow for the second half of the experimental runs (average sediment inflow of $10.6 \mathrm{~g} \mathrm{~s}^{-1}$ ), most probably was due to the settling of the largest sediment particles in the mixing tank.

Sediment outflow (Fig. 3b) during the WSR (average $0.22 \mathrm{~g} \mathrm{~s}^{-1}$ ) and DSR (average $0.59 \mathrm{~g} \mathrm{~s}^{-1}$ ) was 20 - to 30 -fold lower than the sediment inflow. This implied that the bulk of the eroded soil material was deposited on the depositional soil bed. In case of the MR, sediment settling in the depositional area was less effective due to the dispersed nature of the sediment. This resulted in an average sediment outflow of $1.93 \mathrm{~g} \mathrm{~s}^{-1}$, only 6 -fold lower than the sediment inflow.

Throughout all experimental runs, eroded sediment, entering and leaving the depositional area, was enriched in organic carbon, relative to the source soil (Fig. 3c). This enrichment is expressed by the SOC enrichment ratio ( $\left.\mathrm{ER}_{\mathrm{SOC}}\right)$, defined as the ratio of $\mathrm{C}$ content of the eroded soil to that of the source soil. The average $\mathrm{ER}_{\mathrm{SOC}}$ of sediments entering the depositional area was fairly constant $(1.32 \pm 0.05)$. Sediments leaving the depositional area were even more enriched in SOC, with enrichment ratios of $2.304 \pm 0.10,4.74 \pm 0.53$ and $1.72 \pm 0.28$ for WSR, DSR and MR respectively.

\subsection{Mass of deposited sediment and SOC}

The results of the mass calculations are summarized in Tables 1 and 2. The amount of sediment, deposited in the depositional area, was lowest during the WSR $\left(5.66 \times 10^{3} \mathrm{~g}\right)$, resulting from both low sediment in- and outflow (Fig. 3). Roughly 2.5 times more sediment was deposited $\left(1.47 \times 10^{4} \mathrm{~g}\right)$ during the DSR, as high sediment inflow and concurrent low sediment outflow resulted in the deposition of the bulk of a large amount of eroded sediment. During the MR, despite the high sediment inflow, only an intermediate amount of sediment was deposited $\left(9.32 \times 10^{3} \mathrm{~g}\right)$. During the WSR and DSR, the bulk of the eroded sediment was deposited upon entering the depositional area and the amount of deposition decreased rapidly towards the depositional area outlet. During the MR, the mass of deposited sediment also decreased along the direction of the flow, although much less pronounced as during the WSR and DSR. The above-mentioned patterns of erosion, deposition and export 
Table 1. Sediment mass balance of the depositional area for the three simulation experiments.

\begin{tabular}{lcccccc}
\hline Sediment mass balance & \multicolumn{2}{l}{ Wet Soil Runs (WSR) } & \multicolumn{2}{c}{ Dry Soil Runs (DSR) } & \multicolumn{2}{l}{ Mixed Runs (MR) } \\
\hline Total Deposition - M1 (g) & 5662 & $( \pm 446)$ & 14692 & $( \pm 1319)$ & 9317 & $( \pm 457)$ \\
Deposition per unit length - M2 $\left(\mathrm{g} \mathrm{cm}^{-1}\right)$ & & & & & & $( \pm 3.7)$ \\
$\quad$ & 78.9 & $( \pm 1.4)$ & 230.0 & $( \pm 39.9)$ & 89.6 & $( \pm 0.4)$ \\
$\quad$ Zone A & 11.6 & $( \pm 2.2)$ & 40.8 & $( \pm 10.9)$ & 38.6 & $( \pm 0.3)$ \\
$\quad$ Zone B & 4.7 & $( \pm 0.8)$ & 13.3 & $( \pm 7.3)$ & 28.5 & $( \pm 0.1)$ \\
$\quad$ Zone C & 7.6 & $( \pm 1.8)$ & 3.0 & $( \pm 0.4)$ & 17.2 & $( \pm 0.1)$ \\
Sediment Delivery Ratio - M1 $(\%)$ & & & & & &
\end{tabular}

Table 2. SOC mass balance of the depositional area for the three simulation experiments.

\begin{tabular}{|c|c|c|c|c|c|c|}
\hline \multirow{2}{*}{$\begin{array}{l}\text { SOC mass balance } \\
\text { Total deposition - M1 (g) }\end{array}$} & \multicolumn{2}{|c|}{ Wet Soil Runs (WSR) } & \multicolumn{2}{|c|}{ Dry Soil Runs (DSR) } & \multicolumn{2}{|c|}{ Mixed Runs (MR) } \\
\hline & 103 & $( \pm 16)$ & 267 & $( \pm 14)$ & 181 & $( \pm 18)$ \\
\hline Total deposition - M2 (g) & 66 & $( \pm 22)$ & 229 & $( \pm 22)$ & 140 & $( \pm 11)$ \\
\hline \multicolumn{7}{|c|}{ Deposition per unit length $-\mathrm{M} 2\left(\mathrm{~g} \mathrm{~cm}^{-1}\right)$} \\
\hline Zone A & 1.17 & $( \pm 0.02)$ & 4.00 & $( \pm 1.49)$ & 0.38 & $( \pm 0.10)$ \\
\hline Zone B & 0.15 & $( \pm 0.01)$ & 0.62 & $( \pm 0.15)$ & 0.79 & $( \pm 0.10)$ \\
\hline Zone C & 0.07 & $( \pm 0.01)$ & 0.20 & $( \pm 0.09)$ & 0.69 & $( \pm 0.03)$ \\
\hline SOC Delivery Ratio - M1 (\%) & 14.0 & $( \pm 4.4)$ & 10.7 & $( \pm 1.2)$ & 21.9 & $( \pm 3.5)$ \\
\hline
\end{tabular}

were reflected in the sediment delivery ratio (SDR). While most of the eroded sediment was retained in the depositional area during the WSR and DSR (SDRs of $7.6 \%$ and $3.0 \%$ respectively), sediment settling in the depositional area was distinctly less effective during the MR (SDR of 17.2\%).

The average SOC concentration in the deposited sediment, calculated from the balance between SOC in- and outflow, amounted to a steady $1.86 \pm 0.08 \%$. Consequently, for all experimental runs, the mass of deposited SOC was proportional to the mass of deposited sediment (Table 2). For the WSR and DSR, no apparent enrichment or depletion in SOC could be observed between the zones of the depositional area. After the MR, however, sediment deposited at the inlet of the depositional area was clearly depleted in SOC, while the sediment at the area outlet was enriched in SOC. The SOC delivery ratios for the WSR and DSR were two (14.0\%) and three $(10.7 \%)$ times as high as their respective sediment delivery ratios, while with a SOC delivery ratio of $21.9 \%$, the SOC enrichment of the outflow during the MR was less pronounced. The mass of SOC in the deposited sediments, immediately after the experimental runs, was calculated by method M1. After 98 days of $\mathrm{CO}_{2}$-efflux measurements, this amount of SOC had decreased by $20 \%$ and $14 \%$ for the WSR and DSR respectively, as calculated by method M2 (Table 2). For the MR, a decrease of $22 \%$ was observed after only 48 days of $\mathrm{CO}_{2}$-efflux.

The dispersed grain-size distribution of the deposited sediment complements the above analysis of soil redistribution. The sediment deposited in zone A during the WSR and DSR was texturally similar to the original soil material, although slightly coarser (4\% more sand). Further along the flow path (zone B and zone $\mathrm{C}$ ), the deposited sediment was entirely enriched in silt $(+12 \%)$ and depleted in sand $(-12 \%)$. The dispersed grain-size distribution of the sediment deposited during the MR, was identical in all zones with a substantial enrichment in fine particles (13\% depletion in sand and $12 \%$ more silt).

From the additional measurements on the impact of wetting on aggregate structure and carbon distribution, it could be concluded that rapid wetting (slaking treatment) resulted in more important aggregate breakdown: in the slowly wetted soil samples, macro-aggregates $(>250 \mu \mathrm{m})$ constitute $52 \%$ of the dry soil weigh compared to only $39 \%$ for the rapidly wetted soil samples. The slaking treatment resulted mainly in a strong reduction of large macro-aggregates ( $>2000 \mu \mathrm{m}, 13 \%$ compared to $3 \%$ ), concomitant with an increase in micro-aggregates, while the proportion of silt and clay size particles only increased slightly (Fig. 4). Organic $\mathrm{C}$ concentrations were rather similar among aggregate size fractions $>53 \mu \mathrm{m}$ in the slowly wetted soil, while SOC concentration decreased with decreasing aggregate size in the slaked soil samples (Fig. 4).

\subsection{Effects of soil temperature and moisture on $\mathrm{CO}_{2}$-efflux}

Soil temperature and soil moisture are frequently identified as dominant factors, controlling the $\mathrm{CO}_{2}$-efflux (Smith et al., 
a)

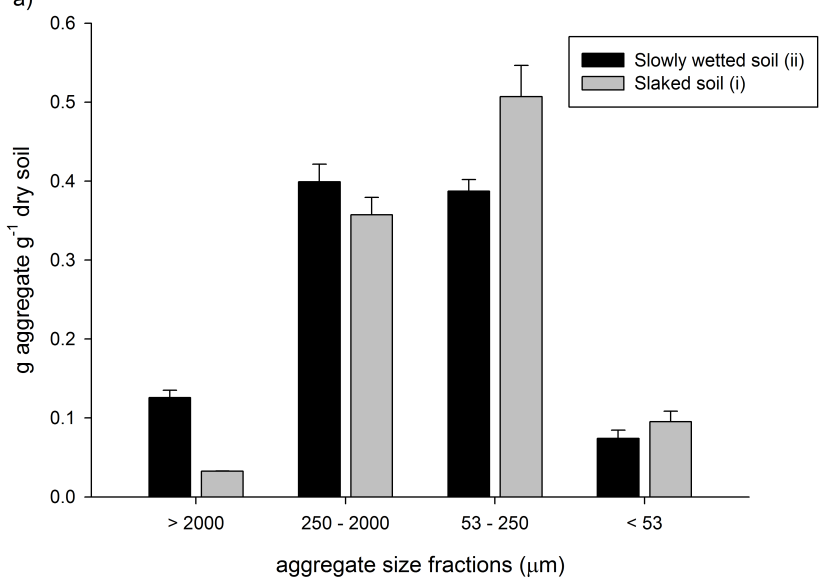

b)

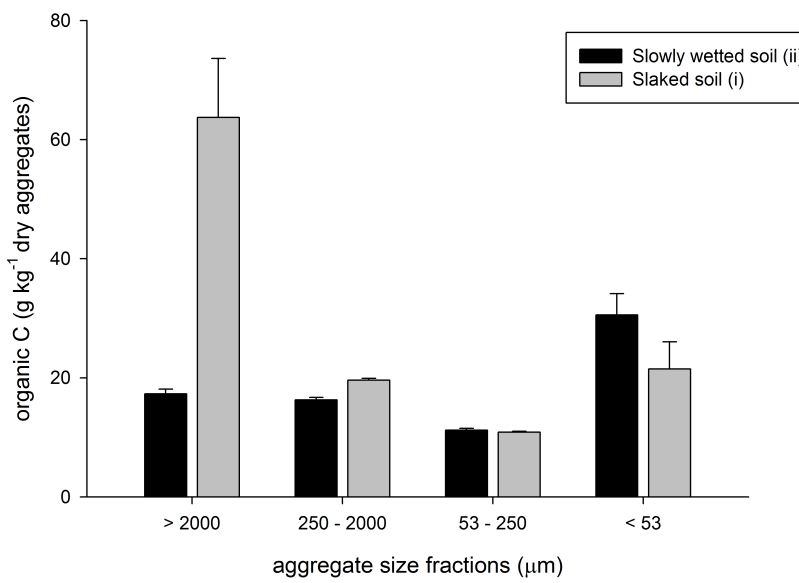

Fig. 4. (a) Aggregate-size distribution for slaked and slowly wetted soil. (b) Organic $\mathrm{C}$ concentration for the aggregate-size classes of the slaked and slowly wetted soil.

2003; Davidson et al., 1998). Therefore a prior analysis of these environmental variables was mandatory to dissociate their influence from any erosional effect on $\mathrm{CO}_{2}$-efflux. During the first 56 days after conducting the WSR and DSR, the soil temperature remained rather constant on all soil cores $\left(15.11 \pm 0.04^{\circ} \mathrm{C}, 15.15 \pm 0.05^{\circ} \mathrm{C}\right.$ and $15.42 \pm 0.07^{\circ} \mathrm{C}$ respectively for soil cores from WSR, DSR and control soils without deposition). Next, a sudden substantial increase in solar insolation and outside air temperature $\left(+10^{\circ} \mathrm{C}\right)$, led to a warming of all soil cores by ca. $2.8^{\circ} \mathrm{C}$. This warmer period coincided with the start of measurements on soil cores from the MR experiments. This, consequently, limited the distinction between the effect of warmer soil temperatures and any erosional effect for the MR. Therefore, a first analysis included only measurements on WSR, DSR and control soil cores during the first 56 days of the measurement period. A repeated measures ANOVA of soil temperatures for this period revealed a significant interaction effect $(F(46,196)=$ $1.55, p=0.021$ ) between experiment (WSR, DSR and control soil cores) and time (56 days of measurements inside the laboratory). Soil temperatures increased by $1.6^{\circ} \mathrm{C}$ on average during the first 15 days after conducting the experiment and remained almost constant thereafter. Comparison at individual time points, however, revealed a more pronounced temperature increase on control soil cores, resulting in an overall significant temperature difference of $0.3^{\circ} \mathrm{C}$ between WSR and DSR soil cores on the one hand and control soil cores on the other hand. When the soil cores were moved to the open air after 77 days, the depositional layers quickly started to dry out while cracks formed on the surface. Repeated measures ANOVA for the outside period, revealed a significant interaction effect $(F(12,69.4)=2.83, p=0.003)$ for soil temperature between experiment and time. In the open air, the soil temperatures varied with air temperature (Fig. 5) and were on average higher than inside the laboratory $\left(16.90 \pm 0.20^{\circ} \mathrm{C}, 16.30 \pm 0.42^{\circ} \mathrm{C}, 16.78 \pm 0.43{ }^{\circ} \mathrm{C}\right.$ and $17.30 \pm 0.48^{\circ} \mathrm{C}$ for WSR, DSR, MR and control soil cores, respectively). Soil cores from DSR were somewhat colder (between $0.5^{\circ} \mathrm{C}-1.0^{\circ} \mathrm{C}$ ) than other soil cores, although the difference was only statistically significant for warmer days. The, initially high, volumetric moisture contents (average $39.0 \pm 0.6 \%$ ) decreased considerably during the week following the experimental runs and equilibrated at $31.9 \pm 0.3 \%$ for the remainder of the measurement period inside the laboratory (Fig. 5). For soil moisture, no interaction $(F(6,48)=$ $1.41, p=0.230)$, nor experiment effect $(F(2,48)=1.58$, $p=0.216)$ was found for the measurements taken in the laboratory after WSR and DSR experiments. Upon exposing the soil cores to wind and outside air temperatures, the soil started to dry, although at different rates depending on experiment. A significant time by experiment interaction effect was found $(F(6,51)=4.03, p=0.002)$. After 7 days in the open air, the average moisture content amounted to $30.6 \pm 1.0 \%, 31.2 \pm 0.7 \%$ and $32.2 \pm 1.4 \%$ for WSR, DSR and control soil cores respectively but only $24.0 \pm 0.4 \%$ for MR soil cores. Thus, during the first 56 days of measurements inside the laboratory, volumetric soil moisture content was similar for all soil cores and was rather constant in time. Soil temperature differences, although significant, were small and not likely to conceal any erosional effects. During the 21 measurement days in open air, soil temperature and moisture were variable in time, depending on weather conditions. Again, no clear significant differences among soil cores were observed, except for the MR soil cores, which dried quickly in open air. Given that conditions were completely different inside and outside the laboratory, further analyses of $\mathrm{CO}_{2}$-efflux were performed separately for both periods.

\section{4 $\mathrm{CO}_{2}$-efflux}

During the initial measurement period (the first 56 days after conducting the experimental runs), the average $\mathrm{CO}_{2}$-efflux amounted to $0.15 \pm 0.01,0.43 \pm 0.02$ and $0.18 \pm 0.01 \times 10^{-6} \mathrm{~mol} \mathrm{CO}_{2}-\mathrm{C} \mathrm{m}^{-2} \mathrm{~s}^{-1}$ for WSR, DSR and 

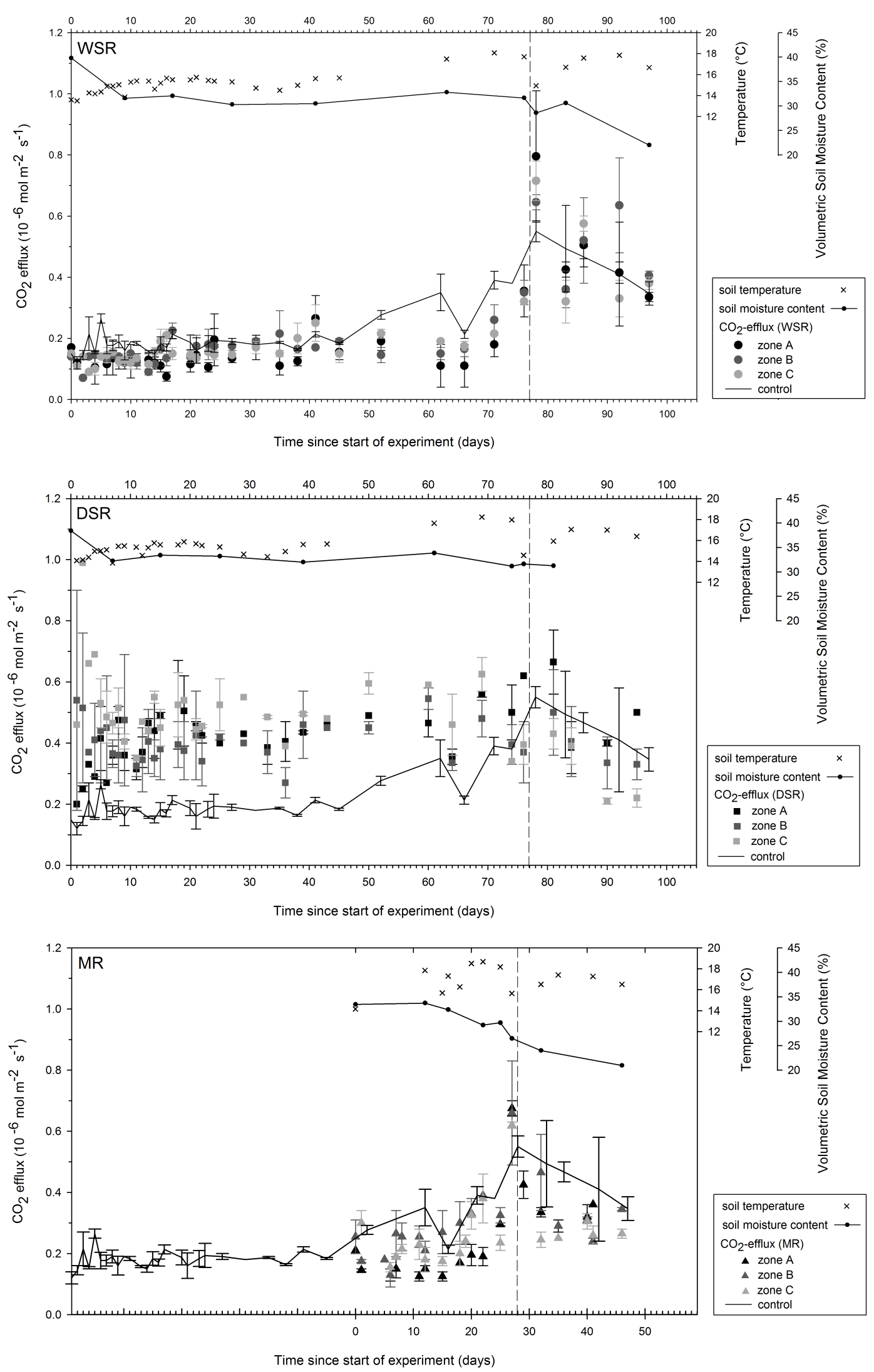

Fig. 5. (a), (b) and (c): $\mathrm{CO}_{2}$-efflux per experiment (WSR, DSR and MR) and per zone of the depositional area (zone A, B and C). The black line connects measurements of $\mathrm{CO}_{2}$-efflux on control soil cores. Soil temperature $\left({ }^{\circ} \mathrm{C}\right.$, crosses) and volumetric soil moisture content $(\%)$ per experiment. The dashed vertical line marks the time at which soil cores were relocated to the outside of the laboratory. 
Table 3. Repeated measures ANOVA of $\mathrm{CO}_{2}$-efflux for the period inside the laboratory (left: analysis of WSR, DSR and control soil cores during 56 days of measurements) and outside the laboratory (right: analysis of WSR, DSR, MR and control soil cores during 21 days of measurements). (Num DF: Numerator degrees of freedom; Den DF: denominator degrees of freedom).

\begin{tabular}{lrrrrrrrrr}
\hline Source of variation & \multicolumn{4}{c}{$\mathrm{CO}_{2}$-efflux (inside) } & \multicolumn{3}{c}{$\mathrm{CO}_{2}$-efflux (outside) } \\
\cline { 2 - 9 } & Num DF & Den DF & $F$ & P-value & Num DF & Den DF & $F$ & P-value \\
\hline Experiment & 6 & 8.49 & 20.02 & 0.0001 & 9 & 47 & 1.85 & 0.0847 \\
Time & 20 & 89.7 & 3.77 & $<0.0001$ & 4 & 47 & 4.85 & 0.0023 \\
Time $\times$ Experiment & 120 & 91.7 & 1.29 & 0.1006 & 36 & 47 & 6.86 & $<0.0001$ \\
\hline
\end{tabular}

control soil cores respectively (Fig. 5). A repeated measures ANOVA of $\mathrm{CO}_{2}$-efflux measurements (Table 3) revealed a significant effect of experiment $(p=0.0001)$. A post-hoc Tukey test for pair wise comparison indicated that, overall, $\mathrm{CO}_{2}$-efflux was significantly higher on soil cores, taken after the DSR experiments, compared to $\mathrm{CO}_{2}$-efflux from WSR and control soil cores $(p<0.0001)$. Despite a significant effect of time, average $\mathrm{CO}_{2}$-fluxes were mostly steady, with larger variability only during the initial measurements on DSR soil cores. No significant difference could be observed between soil cores, sampled in different zones of the depositional area and thus characterized by various amounts of deposition.

As mentioned previously, the soil temperature of all soil cores increased by an average of $2.8^{\circ} \mathrm{C}$, after 56 days of measurements. $\mathrm{CO}_{2}$-efflux increased in subsequent days, with the largest increase measured on control soil cores $\left(+0.12 \times 10^{-6} \mathrm{~mol} \mathrm{CO}_{2}-\mathrm{C} \mathrm{m}^{-2} \mathrm{~s}^{-1}\right.$ on average $)$ compared to WSR and DSR $\left(+0.03\right.$ and $+0.07 \times 10^{-6} \mathrm{~mol} \mathrm{CO}_{2}$ $\mathrm{C} \mathrm{m}^{-2} \mathrm{~s}^{-1}$ on average respectively). This period with higher soil temperatures also coincided with the beginning of measurements on MR soil cores. The initial $\mathrm{CO}_{2}$-efflux on MR soil cores $\left(0.22 \pm 0.01 \times 10^{-6} \mathrm{~mol} \mathrm{CO}_{2}-\mathrm{C} \mathrm{m}^{-2} \mathrm{~s}^{-1}\right)$ was intermediate between the initial $\mathrm{CO}_{2}$-efflux on WSR and DSR soil cores. However there is a large probability that the $\mathrm{CO}_{2}$ efflux was biased by the higher soil temperatures. Noteworthy is the lower than average $\mathrm{CO}_{2}$-efflux on MR soil cores sampled in zone A, close to the inlet of the depositional area $\left(0.15 \pm 0.01 \times 10^{-6} \mathrm{~mol} \mathrm{CO}_{2}-\mathrm{C} \mathrm{m}^{-2} \mathrm{~s}^{-1}\right)$ as compared to an average value of $0.25 \pm 0.02 \times 10^{-6} \mathrm{~mol} \mathrm{CO}_{2}-\mathrm{C} \mathrm{m}^{-2} \mathrm{~s}^{-1}$ on zone $\mathrm{B}$ and $\mathrm{C}$ soil cores.

Upon relocating the soil cores out of the laboratory, a pulse of high $\mathrm{CO}_{2}$-efflux was observed on most of the soil cores with deposited sediment. In the subsequent days, $\mathrm{CO}_{2}$-efflux was quite variable and presumably controlled by the interplay between changing soil temperatures and decreasing soil moisture content. A repeated measures ANOVA (Table 3) revealed an interaction effect $(p<0.0001)$ between experiment and time. Overall, no significant differences between soil cores from different experiments and/or zones could be detected. Average fluxes were highest on WSR and control soil cores $\left(0.44 \pm 0.03\right.$ and $0.44 \pm 0.05 \times 10^{-6} \mathrm{~mol} \mathrm{CO}_{2}-\mathrm{C} \mathrm{m}^{-2} \mathrm{~s}^{-1}$, respectively) compared to DSR soil cores $\mathrm{CO}_{2}$-efflux $\left(0.39 \pm 0.03 \times 10^{-6} \mathrm{~mol} \mathrm{CO}_{2}-\mathrm{C} \mathrm{m}^{-2} \mathrm{~s}^{-1}\right)$ and MR soil cores $\mathrm{CO}_{2}$-efflux $\left(0.31 \pm 0.02 \times 10^{-6} \mathrm{~mol} \mathrm{CO}_{2}-\mathrm{C} \mathrm{m}^{-2} \mathrm{~s}^{-1}\right)$. The latter lower fluxes resulted from $\mathrm{CO}_{2}$-efflux on zone $\mathrm{C}$ soil cores, being smaller than those on zone A and B soil cores, though not statistically significant at all individual time points.

After standardizing the $\mathrm{CO}_{2}$-efflux of the MR experiment to the total time period of 77 days, when measurements were done inside the laboratory, an estimated amount of 12,35 , 15 and $12 \mathrm{~g} \mathrm{CO}_{2}-\mathrm{C} \mathrm{m}^{-2}$ was respired respectively from the WSR, DSR and MR depositional area and a control soil of equal surface area. The linear extrapolation of $\mathrm{CO}_{2}$-efflux measurements on MR soil cores, taken during a 27-day period, over a 77-day period, might, to some extent, lead to an overestimation of the cumulatively respired amount of $\mathrm{CO}_{2}-$ $\mathrm{C}$ from the MR depositional area.

For the 98-day measurement period (inside and outside the laboratory), a cumulative amount of 24,45 and $24 \mathrm{~g} \mathrm{CO}_{2}$ $\mathrm{C} \mathrm{m}^{-2}$ was respired from the WSR, DSR and MR depositional area respectively. The cumulative respiration from the control soils during the same period amounted to $21 \mathrm{~g} \mathrm{CO}_{2}$ $\mathrm{C} \mathrm{m}^{-2}$. For the whole depositional tray, the additional emission of $\mathrm{CO}_{2}-\mathrm{C}$, relative to a control soil (and thus due to erosion/deposition) and expressed as a fraction of the mass of initially deposited SOC, amounted to $4 \%, 12 \%$ and $2 \%$ for WSR, DSR and MR respectively. These values are considerably lower than the estimated decrease of SOC in the deposited sediment, previously calculated as the difference in mass of deposited SOC before and after the $\mathrm{CO}_{2}$-efflux measurements. This implies that high losses of SOC from the deposited sediment are compensated for by lower mineralization rates in the underlying original soil. 


\section{Discussion}

\subsection{Characterization of the erosion and deposition patterns}

The experimental set-up was designed to obtain different patterns of deposition with different characteristics of the deposited sediment, in terms of aggregate distribution, SOC content and its availability to decomposition. As such, the experiments simulated the seasonal variability of erosion and deposition events, typical for the Belgian Loess belt. The characteristics of the deposited sediment are the result of the interplay between the processes of erosion and deposition. During the former, selective entrainment of fine and less dense soil particles is controlled by the transport capacity of the overland flow (Beuselinck et al., 2000; Schiettecatte et al., 2008) while conversely, heavy and coarse soil particles are likely to be deposited early. The soil can also be eroded, transported and deposited in aggregated form (Beuselinck et al., 2000; Meyer et al., 1992; Schiettecatte et al., 2008) while these soil aggregates can possibly disintegrate progressively along their pathway (Le Bissonnais, 1996). Soil organic carbon is redistributed according to the redistribution of soil particles and depending on its availability: as loose soil organic matter, adhered to sediment particles or encapsulated within soil aggregates. As such the eroded soil becomes enriched or, conversely, depleted in SOC in the course of the erosion and deposition processes, resulting in a distinct redistribution pattern of sediment and SOC (Di Stefano and Ferro, 2002).

The differences in the amount of measured sediment and SOC deposition between the experiments (Tables 1 and 2) are in agreement with the objectives of the different experimental set-ups, used to create variations in erosion rate. The high initial moisture content of the soil in the erosion flume during the WSR, impeded the entrainment of large amounts of soil particles, while conversely, during the DSR, slaking of the dry soil aggregates in the erosion flume resulted in soil particles susceptible to water erosion and consequently high erosion rates.

As larger soil aggregates are found to contain a relatively larger portion of more labile soil organic matter (Six et al., 2000), it could be hypothesized that this breakdown of soil aggregates during the DSR, resulted in the prompt exposure of previously encapsulated SOC, which thereupon became available to decomposition.

From the resemblance of the dispersed grain-size distribution of sediment in the WSR and DSR to the texture of the original soil, it can be assumed that, during above-named experiments, the bulk of the eroded and transported soil was deposited in aggregated form upon entering the depositional area. The residual smaller aggregates, enriched in silt, and loose soil particles were deposited towards the outlet of the depositional area. Still, Beuselinck et al. (2000) argued that it is plausible that a significant portion of fine soil particles can be trapped between larger soil aggregates and contraintuitively could be deposited in zone A as well. From the grain-size distribution of the dispersed sediment deposited during the MR, it could be hypothesized that, despite pumpmixing, larger sand grains settled to the bottom of the mixing tank before deposition. Upon entering the depositional area a slight sorting effect could be observed with gradual enrichment of sediment deposits in clay-sized particles and particularly SOC, towards the outlet of the depositional area. Nonetheless, during all experiments, the $\mathrm{C}$ enrichment ratios, measured at the inlet of the depositional area, were higher than 1 and hint at a slight preferential transport of finer soil particles, which are primarily bound to SOM.

The degree of aggregation of the eroded sediment can also explain for the observed difference in sediment and SOC delivery ratios between the experiments (Tables 1 and 2). During the WSR and DSR, the bulk of the eroded soil in aggregated form could not be transported to the outlet. Only a small fraction of probably very fine soil particles, highly enriched in SOC, was exported from the depositional area. However, when the sediment was more dispersed during the MR, the rather large SDR and SOC delivery ratio evidenced the export of a significant portion of fine-sized soil particles and OC. Low SDRs, well below $20 \%$, are not unlikely in a field situation (Steegen, 2001). The latter also implies that it is very important to study SOC dynamics in depositional areas.

\section{2 $\mathrm{CO}_{2}$-efflux as influenced by erosion and deposition}

The range of measured $\mathrm{CO}_{2}$-effluxes in this study (0.04$\left.1.34 \times 10^{-6} \mathrm{~mol} \mathrm{CO}_{2}-\mathrm{C} \mathrm{m}^{-2} \mathrm{~s}^{-1}\right)$ is comparable to measured soil respiration rates of mineral, agricultural soils, reported in the literature (see Raich and Potter, 1995, for a global dataset and e.g. Lohila et al., 2003; Bajracharya et al., 2000 and Tufekcioglu et al., 2001, for specific case studies). In addition, the results of this study were compared with those of three other experimental studies (Jacinthe et al., 2002, 2004; Polyakov and Lal, 2004), specifically addressing the impact of erosion and deposition processes on SOC decomposition (Table 4). It can be seen that the basal soil respiration, expressed as 100-day $\mathrm{CO}_{2}$-efflux of an undisturbed soil (in $\mathrm{g} \mathrm{CO}_{2}-\mathrm{C} \mathrm{kg}^{-1}$ soil), was also, only slightly different between the various studies. Thus, the measured values of $\mathrm{CO}_{2}$-efflux in this study appear to be realistic, when compared to those of field studies.

In Fig. 6, the amount of SOC, initially deposited in the depositional area (M1), is compared to the sum of the cumulative $\mathrm{CO}_{2}-\mathrm{C}$ efflux and the mass of SOC in the deposited sediment at the end of the $\mathrm{CO}_{2}$-efflux measurements (M2). It was found that these SOC mass balances before and after the experiment were very similar for all experiments, i.e. the sum of the SOC still present in the deposited sediments after the experiments and the respired $\mathrm{CO}_{2}-\mathrm{C}$ were very similar to the amount of SOC that was initially deposited. The latter 


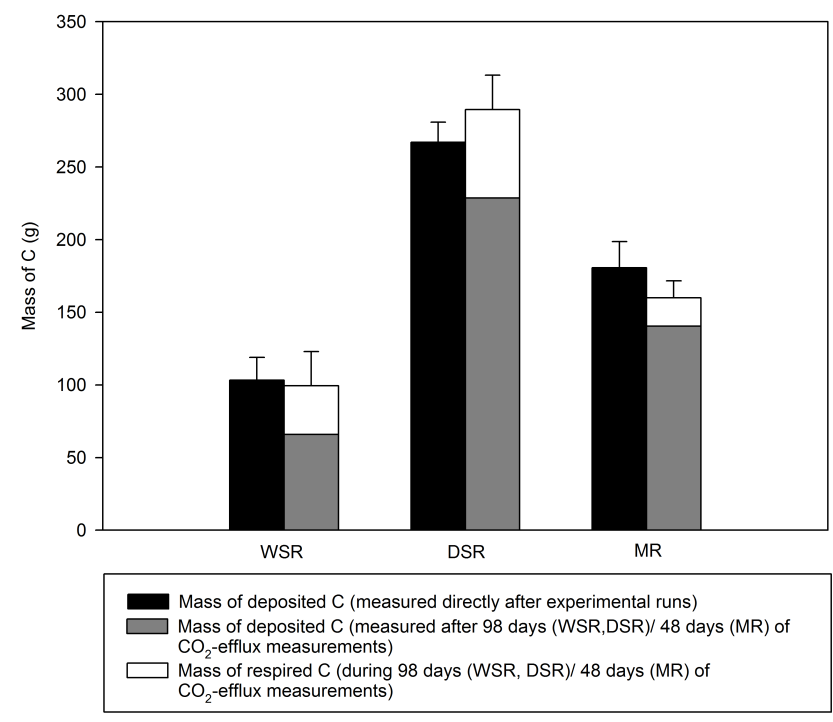

Fig. 6. Comparison between the mass of deposited C, directly after the experimental runs (M1) and the sum of the mass of respired $\mathrm{CO}_{2}-\mathrm{C}$ and the mass of $\mathrm{C}$ in deposited sediments after $\mathrm{CO}_{2}$-efflux measurements (M2).

suggests that the measured $\mathrm{CO}_{2}-\mathrm{C}$ originated to a large extent from the decomposition of SOC in the deposited sediment.

In general, no differences in $\mathrm{CO}_{2}$-efflux were observed between the different zones in the depositional area within the same experiment (except for zone A during the MR). As the amount of deposited sediment differed distinctly between the different zones in the depositional area, the above suggests that the $\mathrm{CO}_{2}$-efflux does not strongly depend on the amount of deposited sediment and that SOC decomposition, contributing to the measured $\mathrm{CO}_{2}$-efflux, mainly takes place in the uppermost layer of the deposited sediments.

Other studies on well-structured soil profiles have shown that significant SOC mineralization can take place at greater depths (Tang et al., 2003; Fierer et al., 2003). However, observations suggest that deposition produces a dense stratified layer of sediment that caps the soil surface (Fox et al., 1998). This will limit gas (and oxygen) diffusion in the soil profile and ultimately result in a decrease of SOC decomposition at greater depths (Schjonning et al., 2003). The above hypothesis however, is not supported by abundant empirical evidence and thus requires further study.

Our analysis shows that the deposition of eroded sediment indeed led to a significant additional $\mathrm{CO}_{2}$-efflux towards the atmosphere during the DSR experiments. This can be attributed to the strong mechanical disruption of dry soil aggregates by slaking upon wetting, possibly leading to the exposure of previously protected SOC and the deposition of significant amount of soil material. However, it should be pointed out that slaking did not lead to a complete disruption of aggregate structure: from grain-size distribution and SDR, it could be argued that the soil is mainly transported and deposited as micro-aggregates, a phenomenon earlier described by Beuselinck et al. (2000). During the WSR experiments, we did not observe a significant increase of $\mathrm{CO}_{2}$-efflux: during these experiments, soil disruption was much less intense. Aggregates were transported and deposited in more or less intact form. Hence, no major effect on $\mathrm{CO}_{2}$-efflux should be expected. The results of the additional measurements on the impact of wetting on aggregate structure and carbon distribution are supportive of the above conclusion: in comparison to slow wetting, slaking lead to a stronger disruption of easily degradable macroaggregates into much more stable microaggregates. Eventually, this could have led to the exposure of the carbon-rich cementing material binding the macro-aggregates (microbial and plant-derived polysaccharides, roots and fungal hyphae) thereby increasing the potential for mineralization during the erosion/transport/deposition process (according to aggregate hierarchy theory of Tisdall and Oades , 1982). Further studies are however clearly necessary to confirm this hypothesis.

As the time between rewetting of the soil and carrying out the experiment was less than $24 \mathrm{~h}$, the prolonged difference in $\mathrm{CO}_{2}$-efflux could not be attributed to the soil bed preparation. During the $\mathrm{MR}$, the additional $\mathrm{CO}_{2}$-efflux was also comparatively small. At first sight this is unexpected, given the fact that mechanically dispersed soil material was used: a possible explanation for this minor effect is that a large fraction of the potentially mineralizable SOC was exported from the depositional area, leaving a more stable SOC fraction at the soil surface in the deposited sediments. It is noteworthy that, when accounting for the possible overestimation of cumulatively respired $\mathrm{CO}_{2}-\mathrm{C}$ from the $\mathrm{MR}$ depositional area, by extrapolating the measured $\mathrm{CO}_{2}$-effluxes, this observation is even more strongly pronounced. Our data thus confirm the findings of Jacinthe et al. (2004): the effect of erosion on SOC mineralization may depend considerably on the type of erosion event and the soil conditions at the moment when erosion occurs.

From day 60 on, a temperature rise in the laboratory building due to sunny spring weather (and despite temperature control), led to a similar increase of soil temperatures on all soil cores. Concurrent with this observation an increase of $\mathrm{CO}_{2}$-efflux was observed for all cores. Given the fact that this increase of $\mathrm{CO}_{2}$-efflux and soil temperature were also observed for the control soil cores, the increased $\mathrm{CO}_{2}$-efflux most likely could be attributed to the higher soil temperatures. However, it could also be observed that the increased temperatures induced drying and cracking of the soil surfaces, possibly causing the release to the atmosphere of an amount of $\mathrm{CO}_{2}$, that was previously trapped within the soil pore space. This could explain for the decrease of $\mathrm{CO}_{2}$-efflux from day 78 onwards, despite continued high temperatures.

The fraction of eroded SOC that was rapidly mineralized after deposition ( $<100$ days) varied between 14 and $22 \%$. These amounts are comparable to those reported in other studies, often with a completely different design (Table 4). 
Table 4. Comparison of this study with three other experimental studies, addressing the impact of erosion and deposition processes on SOC decomposition. Results have been recalculated in function of the reported measurements and dimensions used.

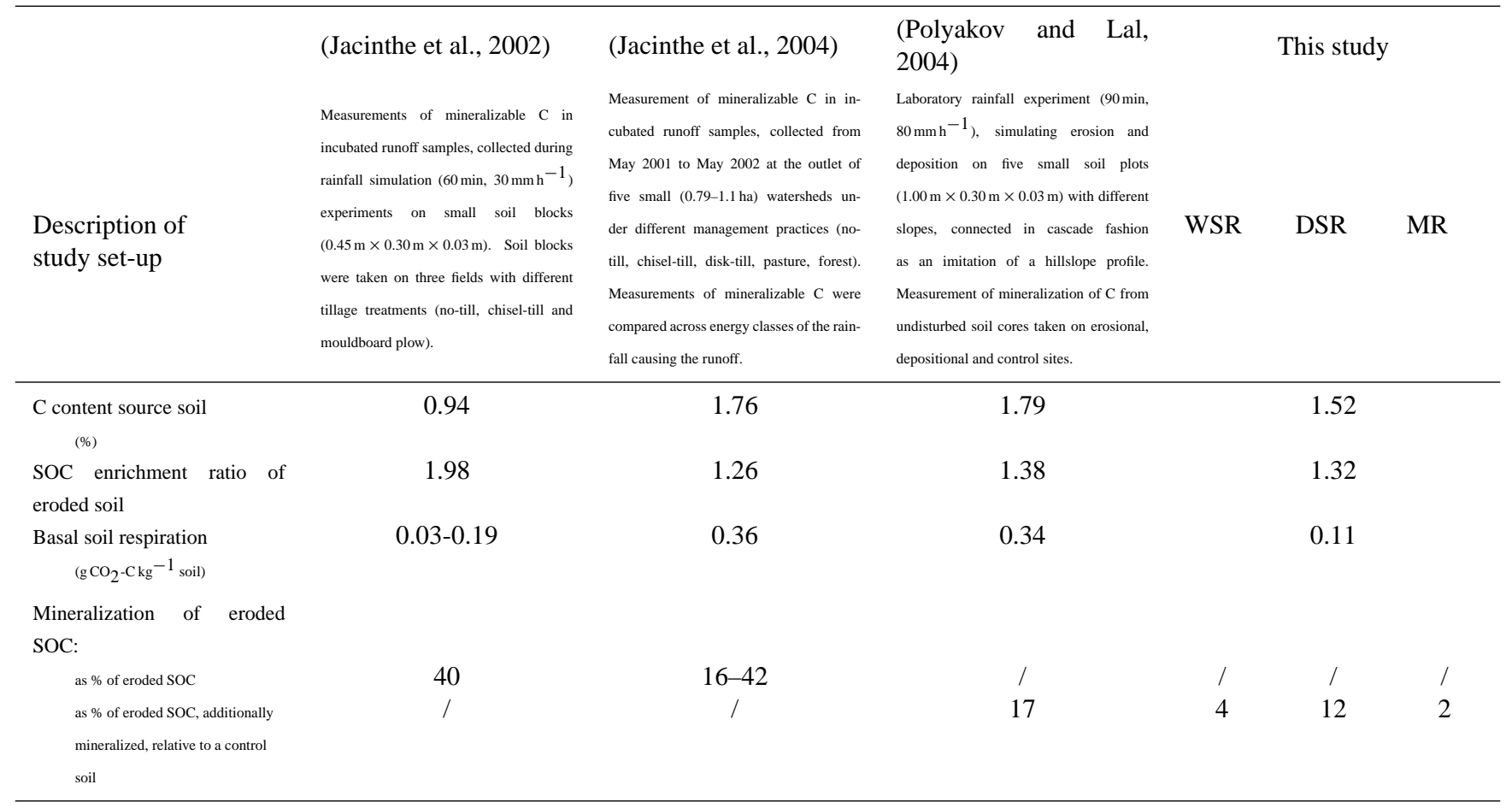

At first sight, these findings imply that erosion and deposition may indeed lead to a significant release of SOC to the atmosphere, thereby contradicting the findings of Van Oost et al. (2007).

However, expressed as the additional $\mathrm{CO}_{2}$-efflux relative to a control soil, the net effect of erosion on SOC is much smaller (between 2 and 12\%). The most likely explanation for this finding is that the presence of a thick depositional layer hampers mineralization below the top layer, which is compensated for by an increased $\mathrm{CO}_{2}$-efflux from the deposition layers and this to a different extent, depending on the conditions in the experiment. This finding shows that, when the overall effect of erosion is to be assessed, one cannot solely focus on the properties of the deposited sediments. The presence of the latter appear to affect the functioning of the whole soil system, so part of the mineralization of SOC within the deposited layer is offset by a decrease in mineralization deeper within the soil profile. Our results should therefore be compared to those reported by Polyakov and Lal (2004), who incubated intact soil cores with layers of deposited sediment and estimated $16 \%$ of eroded and redeposited $\mathrm{C}$ to be additionally susceptible to mineralization.

\subsection{Implications for field-scale C-fluxes}

The implications of the results of this study for field-scale Cfluxes are difficult to determine because of the simplification of the experimental system compared to a real world situation where variations in temperature, moisture as well as additional effects of plant growth, field management, etc. can be expected. Nevertheless, as experimental conditions (SOC enrichment, amount of deposition and measured SDR) were representative for field conditions, a tentative extrapolation of the results of this study can be indicative for effects of erosion and deposition on SOC in a field situation. Hence, Fig. 7 presents a simple SOC budget of our system with $\mathrm{C}$ losses as a result of export from the system and possible $\mathrm{C}$ losses or gains due to changing $\mathrm{C}$-efflux in the area of deposition. In general, small erosional events on a moist and well-aggregated soil (represented by WSR) have only a minor effect on C-loss, which is mainly resulting from sediment delivery. Erosion of a dry soil could lead to a distinct Closs by additional respiration from SOC, previously occluded in broken-down soil aggregates. If the eroded soil is highly dispersed, the main loss of SOC occurs by export from the system. It can, however, be hypothesized that an additional amount of SOC is lost by respiration during the dispersion process or after export.

Although this study contributed in estimating potential mineralization of eroded SOC after deposition and SOC delivery in function of the erosional event, additional research is required to obtain information on the unknown fluxes of $\mathrm{CO}_{2}-\mathrm{C}$ at erosional sites and in distant depositional basins and fluvial systems. To integrate these results into a 


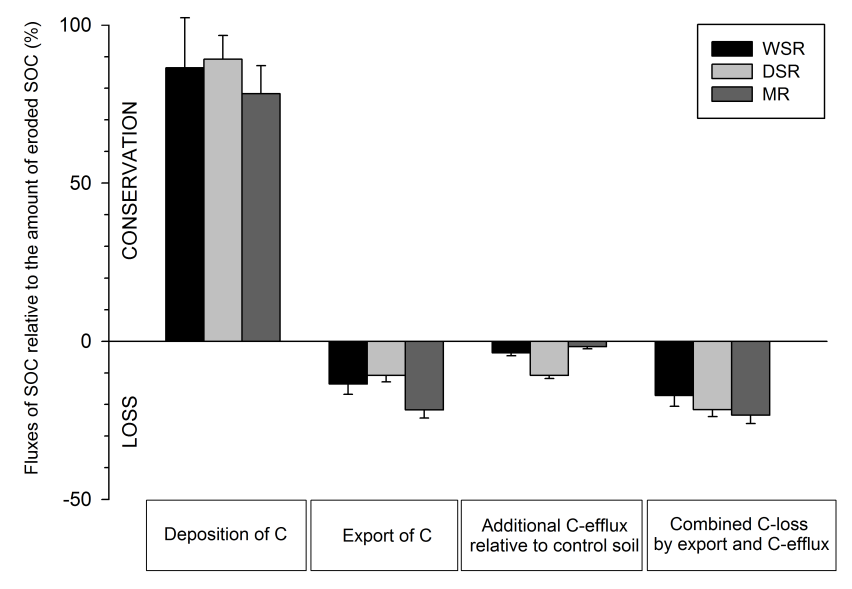

Fig. 7. Fate of eroded SOC (\%) in the three simulation experiments, expressed relative to the total amount of eroded SOC.

C-balance on longer timescales, account should be taken of the spatial patterns of soil redistribution, spatial variation of SOC input and depth-dependent decomposition of organic matter in soils.

\section{Conclusions}

In this study, the effect of erosion, transport and subsequent deposition on the mineralization of SOC was experimentally quantified. During a laboratory experiment, three types of erosional events were simulated, each of which was designed to produce a different amount of eroded soil material with a different degree of aggregation. During a 98-day period, insitu measurements of $\mathrm{CO}_{2}$-efflux on undisturbed soils with a layer of deposited soil material, and this under field conditions, allowed us to quantify more accurately how erosion affects $\mathrm{C}$-exchange between the soil and the atmosphere.

Depending on the initial conditions of the soil and the intensity of the erosion process, a significant fraction of eroded SOC was mineralized after deposition (between 14 and 22\% of eroded SOC). Slaking of initially dry soil aggregates during the process of erosion, could have led to the exposure of previously encapsulated SOC and subsequent mineralization of this SOC after deposition. On the contrary, when the initial soil was moist and well-structured, soil was eroded and transported in aggregated form and no major effect on $\mathrm{CO}_{2}$-efflux was observed. When the soil was completely dispersed, prior to the experiments, a large fraction of sediment and potentially mineralizable SOC was exported, resulting in a minor effect on $\mathrm{CO}_{2}$-efflux in the depositional area.

However, results also suggest that deposition produces a dense stratified layer of sediment that caps the soil surface and leads to a decrease in SOC decomposition in deeper soil layers. The latter implies that in order to assess the net effect of erosion on SOC, the functioning of the whole soil system needs to be taken into account. As such, soil redistribution processes contributed to an additional emission of only 2 to $12 \%$ of total $\mathrm{C}$ contained in the deposited sediment.

Further research is required to determine the effect of erosion on SOC at erosional sites and assess the fate of eroded SOC, exported to fluvial systems and distant depositional basins.

Acknowledgements. The research carried out for this paper was funded by the Fund for Scientific Research Flanders (F. W. O. Vlaanderen). Their support is gratefully acknowledged.

Edited by: K. Küsel

\section{References}

Amundson, R.: The carbon budget in soils, Annu. Rev. Earth Pl. Sc., 29, 535-562, 2001.

Bajracharya, R. M., Lal, R., and Kimble, J. M.: Diurnal and seasonal $\mathrm{CO}_{2}-\mathrm{C}$ flux from soil as related to erosion phases in central Ohio, Soil Sci. Soc. Am. J., 64, 286-293, 2000.

Berhe, A. A., Harte, J., Harden, J. W., and Torn, M. S.: The significance of the erosion-induced terrestrial carbon sink, Bioscience, 57, 337-346, 2007.

Beuselinck, L., Govers, G., Steegen, A., Hairsine, P. B., and Poesen, J.: Evaluation of the simple settling theory for predicting sediment deposition by overland flow, Earth. Surf. Proc. Land., 24, 993-1007, 1999.

Beuselinck, L., Steegen, A., Govers, G., Nachtergaele, J., Takken, I., and Poesen, J.: Characteristics of sediment deposits formed by intense rainfall events in small catchments in the Belgian Loam Belt, Geomorphology, 32, 69-82, 2000.

Beyer, L., Frund, R., Schleuss, U., and Wachendorf, C.: Colluvisols under cultivation in Schleswig-Holstein, 2. Carbon Distribution and soil organic-matter composition, Z. Pflanz. Bodenkunde, 156, 213-217, 1993.

Cole, J. J. and Caraco, N. F.: Carbon in catchments: connecting terrestrial carbon losses with aquatic metabolism, Mar. Freshwater Res., 52, 101-110, 2001.

Davidson, E. A., Belk, E., and Boone, R. D.: Soil water content and temperature as independent or confounded factors controlling soil respiration in a temperate mixed hardwood forest, Global Change Biol., 4, 217-227, 1998.

De Gryze, S., Bossuyt, H., Six, J., Van Meirvenne, M., Govers, G., and Merckx, R.: Factors controlling aggregation in a minimum and a conventionally tilled undulating field, Eur. J. Soil Sci., 58, 1017-1026, 2007.

Di Stefano, C. and Ferro, V.: Linking clay enrichment and sediment delivery processes, Biosyst. Eng., 81, 465-479, 2002.

Elliott, E. T.: Aggregate structure and carbon, nitrogen and phosphorus in native and cultivated soils, Soil Sci. Soc. Am. J., 50, 627-633, 1986.

Fierer, N., Allen, A. S., Schimel, J. P., and Holden, P. A.: Controls on microbial $\mathrm{CO}_{2}$ production: a comparison of surface and subsurface soil horizons, Global Change Biol., 9, 1322-1332, 2003.

Fox, D. M., Le Bissonnais, Y., and Bruand, A.: The effect of ponding depth on infiltration in a crusted surface depression, Catena, 32, 87-100, 1998. 
Govers, G., Everaert, W., Poesen, J., Rauws, G., Deploey, J., and Lautridou, J. P.: A long flume study of the dynamic factors affecting the resistance of a loamy soil to concentrated flow erosion, Earth Surf. Proc. Land., 15, 313-328, 1990.

Govers, G.: Time-dependency of runoff velocity and erosion - the effect of the initial soil-moisture profile, Earth Surf. Proc. Land., 16, 713-729, 1991.

Gregorich, E. G., Greer, K. J., Anderson, D. W., and Liang, B. C.: Carbon distribution and losses: erosion and deposition effects, Soil Till. Res., 47, 291-302, 1998.

Harden, J. W., Sharpe, J. M., Parton, W. J., Ojima, D. S., Fries, T. L., Huntington, T. G., and Dabney, S. M.: Dynamic replacement and loss of soil carbon on eroding cropland, Global Biogeochem. Cy., 13, 885-901, 1999.

Hedeker, D. and Gibbons, R. D.: Longitudinal data analysis, 1st edition, John Wiley \& Sons, Hoboken, NJ, 360 pp., 2006.

Jacinthe, P. A., Lal, R., and Kimble, J. M.: Organic carbon storage and dynamics in croplands and terrestrial deposits as influenced by subsurface tile drainage, Soil Sci., 166, 322-335, 2001.

Jacinthe, P. A., Lal, R., and Kimble, J. M.: Carbon dioxide evolution in runoff from simulated rainfall on long-term no-till and plowed soils in southwestern Ohio, Soil Till. Res., 66, 23-33, 2002.

Jacinthe, P. A., Lal, R., Owens, L. B., and Hothem, D. L.: Transport of labile carbon in runoff as affected by land use and rainfall characteristics, Soil Till. Res., 77, 111-123, 2004.

Jobbagy, E. G. and Jackson, R. B.: The vertical distribution of soil organic carbon and its relation to climate and vegetation, Ecol. Appl., 10, 423-436, 2000.

Kemper, W. D., Rosenau, R., and Nelson, S.: Gas displacement and aggregate stability of soils, Soil Sci. Soc. Am. J., 49, 25-28, 1985.

Lal, R.: Soil erosion and the global carbon budget, Environ. Int., 29, 437-450, 2003.

Le Bissonnais, Y.: Aggregate stability and assessment of soil crustability and erodibility, 1. Theory and methodology, Eur. J. Soil Sci., 47, 425-437, 1996.

Littell, R. C., Henry, P. R., and Ammerman, C. B.: Statistical analysis of repeated measures data using SAS procedures, J. Anim. Sci., 76, 1216-1231, 1998.

Liu, S. G., Bliss, N., Sundquist, E., and Huntington, T. G.: Modeling carbon dynamics in vegetation and soil under the impact of soil erosion and deposition, Global Biogeochem Cy., 17, 1074, doi:10.1029/2002GB002010, 2003.

Lohila, A., Aurela, M., Regina, K., and Laurila, T.: Soil and total ecosystem respiration in agricultural fields: effect of soil and crop type, Plant Soil, 251, 303-317, 2003.

Meyer, L. D., Line, D. E., and Harmon, W. C.: Size characteristics of sediment from agricultural soils, J. Soil Water Conserv., 47, 107-111, 1992.

Polyakov, V. O. and Lal, R.: Soil erosion and carbon dynamics under simulated rainfall, Soil Sci., 169, 590-599, 2004.

Raich, J. W. and Potter, C. S.: Global patterns of carbon-dioxide emissions from soils, Global Biogeochem. Cy., 9, 23-36, 1995.
Ritchie, J. C. and McCarty, G. W.: (137)Cesium and soil carbon in a small agricultural watershed, Soil Till. Res., 69, 45-51, 2003.

Schiettecatte, W., Gabriels, D., Cornelis, W. M., and Hofinan, G.: Impact of deposition on the enrichment of organic carbon in eroded sediment, Catena, 72, 340-347, 2008.

Schjonning, P., Thomsen, I. K., Moldrup, P., and Christensen, B. T.: Linking soil microbial activity to water- and air-phase contents and diffusivities, Soil Sci. Soc. Am. J., 67, 156-165, 2003.

Six, J., Paustian, K., Elliott, E. T., and Combrink, C.: Soil structure and organic matter: I. Distribution of aggregate-size classes and aggregate-associated carbon, Soil Sci. Soc. Am. J., 64, 681-689, 2000.

Smith, K. A., Ball, T., Conen, F., Dobbie, K. E., Massheder, J., and Rey, A.: Exchange of greenhouse gases between soil and atmosphere: interactions of soil physical factors and biological processes, Eur. J. Soil Sci., 54, 779-791, 2003.

Smith, S. V., Sleezer, R. O., Renwick, W. H., and Buddemeier, R.: Fates of eroded soil organic carbon: Mississippi basin case study, Ecol. Appl., 15, 1929-1940, 2005.

Stallard, R. F.: Terrestrial sedimentation and the carbon cycle: Coupling weathering and erosion to carbon burial, Global Biogeochem. Cy., 12, 231-257, 1998.

Steegen, A.: Sediment deposition in and export from small agricultural catchments., Institute for Earth and Environmental Sciences, K. U. Leuven, Leuven, 220 pp., 2001.

Steegen, A., Govers, G., Takken, I., Nachtergaele, J., Poesen, J., and Merckx, R.: Factors controlling sediment and phosphorus export from two Belgian agricultural catchments, J. Environ. Qual., 30, 1249-1258, 2001.

Tang, J. W., Baldocchi, D. D., Qi, Y., and Xu, L. K.: Assessing soil $\mathrm{CO}_{2}$ efflux using continuous measurements of $\mathrm{CO}_{2}$ profiles in soils with small solid-state sensors, Agr. Forest Meteorol., 118, 207-220, 2003.

Tisdall, J. M. and Oades, J. M.: Organic matter and water stable aggregates in soils, J. Soil Sci., 33, 141-163, 1982.

Tufekcioglu, A., Raich, J. W., Isenhart, T. M., and Schultz, R. C.: Soil respiration within riparian buffers and adjacent crop fields, Plant Soil, 229, 117-124, 2001.

Van Oost, K., Quine, T. A., Govers, G., De Gryze, S., Six, J., Harden, J. W., Ritchie, J. C., McCarty, G. W., Heckrath, G., Kosmas, C., Giraldez, J. V., da Silva, J. R. M., and Merckx, R.: The impact of agricultural soil erosion on the global carbon cycle, Science, 318, 626-629, 2007.

Yoo, K., Amundson, R., Heimsath, A. M., and Dietrich, W. E.: Erosion of upland hillslope soil organic carbon: coupling field measurements with a sediment transport model, Global Biogeochem. Cy., 19, GB3003, doi:10.1029/2004GB002271, 2005.

Zhang, J. H., Quine, T. A., Ni, S. J., and Ge, F. L.: Stocks and dynamics of SOC in relation to soil redistribution by water and tillage erosion, Global Change Biol., 12, 1834-1841, 2006. 